\title{
Health information work and the enactment of care in couples and families affected by Multiple Sclerosis
}

\begin{abstract}
Given the considerable emphasis placed on informed choice, the management of health information has become an increasingly important part of living with chronic illness. This paper explores the intra-familial dynamics of managing health information in the context of chronic illness. Drawing on 77 interviews with people affected by Multiple Sclerosis in the UK (patients, partners, family members and close friends), we show how families develop their own idiosyncratic information practices, including the careful, at times strategic, seeking, sharing and withholding of information. We describe how one individual, most commonly either the patient or their partner, often takes primary responsibility for managing growing quantities of health information. Doing this is a complex task, yet its dynamics within the family unit remain invisible and unacknowledged. In this paper we: (a) stress the importance of understanding information management in chronic illness as a collective process across all those affected, patients as well as carers; (b) conceptualise the process of managing health information in this context as 'health information work'; and (c) analyse it as part of the wider care practices families engage in and as a form of care in its own right.
\end{abstract}




\section{Introduction}

High quality, appropriate and sympathetically communicated information has long been recognised as an essential component of good healthcare (McIntosh, 1974; Reynolds, 1978; Ley, 1982). As patient choice and empowerment have come to dominate healthcare policy and associated discourse, providing patients with the information necessary to make these choices has taken on a new impetus (Coulter et al., 1999; Coulter, 2010). Increasingly, debates around the provision of health information have come to revolve around digital technologies, which are credited with having the potential to transform health communication, empower patients and inform choice in a cost-effective and efficient manner (Powell and Boden, 2012).

However, health-related information, either online or off, does not inform decision-making in a linear or controllable fashion. People's health information practices are shaped by numerous factors, including family structures and relationships, personal circumstances and preferences, health status, age, gender, education and income (Kivits, 2004; Nettleton et al., 2004; Ayers and Kronenfeld, 2007). Health information can, moreover, have profound implications for people's sense of identity, social interaction and relationships (Ziebland, 2004; Orgad, 2006; Hinton et al., 2010). For those with serious illness, information about their condition is rarely neutral. Reports of new research can trigger a wave of hope, whereas reading about someone's physical deterioration can prompt feelings of despair (Ziebland and Wyke, 2012). Furthermore, contrary to the policy emphasis on providing patients with ever more information, some people actively avoid health-related information (Henwood et al., 2003; Mazanderani et al., 2012).

To date, the individual patient has almost always been the primary unit of analysis in research on people's health information practices. This is problematic for a number of reasons. When 
faced with health concerns, people rarely act in isolation, but engage in complex information practices involving their family, friends and wider social circle (McKinlay, 1972; Scambler et al., 1981). With chronic illness, family members and close friends play a crucial part in people's healthcare practices, including seeking out, sharing and managing information (Corbin and Strauss, 1984; Mutch, 2010; Washington et al., 2011). In recognition of this, researchers are paying more attention to the information needs and preferences of informal 'carers' (in the UK) or 'caregivers' (in the US) - usually a close family member or spouse of the person with the illness (Tuffrey and Finlay, 2002; Kinnane and Milne, 2010; Powell et al., 2010; Sillence et al., 2015). However, here too, the analysis has tended to focus on the carers themselves, rather than how they manage information within and across relational units.

In contrast, this paper explores the inter-relational and particularly inter-familial dynamics of health information practices in the context of chronic illness. More specifically, it analyses how couples and families affected by Multiple Sclerosis (MS) - an inflammatory disorder of the brain and spinal cord that typically affects young adults (Compston and Coles, 2008) respond to and manage health-related information within the family unit.

We conducted a thematic analysis of 77 interviews with family members, partners, friends and patients collected in the UK between 2011 and 2013, focusing on how people spoke of health information practices (online and off) in relation to their spouses, families, and friends. We found that dealing with health information in the context of living with MS is neither straightforward nor easy - it is time-consuming, requires knowledge of medicine and healthcare, computing and communication skills, emotional sensitivity and awareness. Thus, we suggest that managing health information should be recognised as an important part of the work of living with chronic illness (Strauss and Corbin, 1985; Corbin and Strauss, 1988). 
It is widely recognised that living with and caring for someone with a chronic illness entails considerable work. Strauss' and Corbin's (1985) much cited schema distinguishes between the work required to manage illness (e.g. treatment regimens, crisis management), 'everyday life' work (e.g. housekeeping tasks, child rearing), and the 'biographical' work of continually restructuring one's sense of self and identity. Another distinction often drawn is the one between 'body work' and 'emotion work', with a rich corpus of sociological research on both of these in paid and unpaid healthcare contexts (James, 1992; Thomas et al., 2002; England and Dyck, 2011; Riley and Weiss, 2016). Clearly, health information management is implicated in all the above, but, following-on from research in information science (Hogan and Palmer, 2005; Souden, 2008), we argue that health information work cannot be collapsed into or reduced to any one of them, but rather constitutes its own, increasingly important, category of work that needs to be analysed on its own terms.

In this paper, we describe how couples and families affected by MS develop their own, often idiosyncratic, information practices, including the careful, at times strategic, seeking, sharing and withholding of information. We show how health information work is not evenly distributed, with one person (usually either the patient or their partner) often taking primary responsibility for managing the flow of information into, within and beyond the family. Furthermore, in the context of life-altering conditions, such as MS, we suggest that information work is not only an important part of the wider care practices families engage, but as a relational activity constitutes a form of care in its own right.

Below we present a brief overview of the extant literature on the health information practices of people affected by MS, both patients and informal carers. Next, we describe our methods. 
The combined findings and discussion sections: a) provide a high-level overview of the interrelational dynamics of health information work in the context of couples and families affected by MS; b) outline the intra-familial distribution of health information work; c) explore the relationship between health information work and care, and propose health information work be considered a form of care in its own right.

\section{Living with MS: patients' and carers' information practices}

MS is a neurological disease of uncertain aetiology, with unpredictable symptoms and prognosis (McAlpine and Compston, 2005). It is a debilitating condition that usually progresses over time, resulting in some form of permanent disability (Tremlett et al., 2006). At present, there is no cure and available therapies are often accompanied by side-effects (Murray, 2006). People affected by MS, both patients and their family, live with a great deal of uncertainty and need to constantly adapt, at times rapidly, to changing circumstances. This often requires making radical changes to their life, for example, altering where they live, their employment and the kind of activities they engage in. In addition, MS has profound implications for patients' and their family members' sense of self, including their physical and emotional relationships with others (Robinson, 1990; Dyck, 1995; Boeije et al., 2002; Green et al., 2007).

Researchers have been exploring the experiences of people affected by MS since the late 1950s (Talley, 2008, pp.84-110). More recently, in keeping with the wider contemporary emphasis on informed decision-making and the role that digital technologies can play in this, increasing attention is being paid to the information needs and practices of people affected by MS. Previous work shows that while healthcare practitioners remain the most trusted source of information, patients get information from different sources, including mainstream media, 
MS charities, and increasingly the internet (Hepworth and Harrison, 2004; Lode et al., 2007; Marrie et al., 2013; Colombo et al., 2014; Synnot et al., 2014). Moreover, the types of information people search for are incredibly diverse, ranging from information about the disease, research and treatments (e.g. causes of MS, clinical studies, different therapies and side-effects), through to information about living with the condition (e.g. social services and support, employment and MS, disability aids, other people's experiences, relationships, intimacy and sexuality).

The period around diagnosis is a particularly critical time where people affected by MS both desire and can be deeply, sometimes negatively, affected by information (Wollin et al., 2000; Lode et al., 2007; Bogosian et al., 2009; Colombo et al., 2014). One consequence of this is that during the early stages of the disease some people develop information avoidance strategies (Johnson, 2003; Colombo et al., 2014), while for others it can be a period of active information seeking (Synnot et al., 2014). As the initial shock of diagnosis dissipates and people's knowledge about their condition grows, they increasingly 'self-regulate' their online searches, showing different patterns of web use and a more selective use of search terms (Synnot et al., 2014). Later on, as symptoms deteriorate and the disease progresses, it is not unusual for MS patients to once again avoid certain types of information (Colombo et al., 2014).

While the majority of studies focus on patients, there is a sizeable body of literature on the experiences of people who care for a family member with MS (Boeije et al., 2003; Cheung and Hocking, 2004; Bogosian et al., 2009; Mutch, 2010; Hughes et al., 2013). Allied to a more wide-ranging acknowledgement of the importance of informal care work, research focused on carers usually centres on developing a better understanding of their needs in order 
to improve service provision. Some of this work has stressed the reciprocal nature of caring relations, with both 'carer' and 'cared-for' providing different forms of care and support to each other (Boeije et al., 2003; Richardson et al., 2007). Indeed, even the designation 'carer' can be problematic, with some spouses and family members of people with MS preferring to emphasise identities associated with their more general relationship, such as 'husband' or 'mother', on the grounds that their caring functions are already entailed in these designations and should not be artificially separated from them (Hughes et al., 2013).

Among research focused on informal carers, some attention has been given to their distinctive information needs (Corry, 2009). This research shows that family members of people with MS - as with conditions such as stroke (Low et al., 1999, p.720) and Parkinson's disease (Williamson et al., 2008, p.586) - repeatedly stress that information not only plays an important role in how they cope with their loved one's condition, but also in how they care for them (Wollin et al., 2006). Our paper contributes to this literature through its focus on how people affected by MS manage health-related information not as individuals, but as couples and families. Furthermore, existing research has tended to treat the relationship between information and care as a functional one - where 'better', meaning more accurate and appropriately communicated, information straightforwardly equates to better care. In contrast, we unpack the rather more complex relationship between information work and care that is to be found in the context of families living with MS. 


\section{Methods}

This paper draws on three UK-based studies carried out between June 2011 and February 2013 as part of the Internet Patient Experiences (http://ipexonline.org) programme funded by the National Institute for Health Research (NIHR) under its Programme Grants for Applied Research funding scheme (RP-PG-0608-10147). It brings together the MS-related research of this broader programme of work through a thematic analysis of 77 interviews with people affected by MS (65 family members or friends, and 12 patients). See Table 1 for further information.

Although conducted independently, the studies complement each other. Study A is an indepth qualitative research project on experiences of caring for a family member or friend with MS. Study B concentrated on how people affected by MS (patients and family members) used the internet in relation to their or their loved one's health. Study C analysed informal carers' reflections and real-time responses to different forms of health experiences shared online.

\section{Recruitment and Consent}

The studies were advertised through newspapers, posts on MS charity websites and mailing lists (e.g. the MS Society, MS Trust, Shift.MS), carers' groups, and existing contacts. After making initial contact with the relevant research team, potential participants were given written information about the study and had opportunities to ask questions. Written or emailed consent was taken in all three studies. Interviews were audio or video-recorded, and transcribed verbatim. Participants were from a range of socio-economic and ethnic backgrounds and lived in a variety of locations across England and Scotland. Formal ethical approval was received for all three studies: Study A was approved for multi-site recruitment 
by the Berkshire Research Ethics Committee; Study B was approved by Warwick Medical School's Biomedical and Scientific Research Ethics Committee; and Study C by Northumbria University’s Psychology Department Ethics Review Committee. Below we briefly describe the methods used in each study.

Participants who take part in qualitative interview-based studies are self-selecting. Having or caring for someone with MS can further restrict people's availability and influence their willingness to take part in research. We scheduled interviews to suit the participants, endeavouring to recruit as wide a range of people as possible in terms of age, ethnicity, gender, and length of time since diagnosis. Some categories of participant, such as children and young people affected by MS, siblings and friends, were more difficult to recruit. For more detail, see Table 1 .

\section{Study A: Experiences of family members and friends of people with $M S$}

Study A, carried out by NH, was a qualitative interview study on the experiences of family members and friends of people with MS. Between June 2011 and January 2012, CH conducted 40 narrative interviews with people who self-identified as a relative or friend of someone with MS. A maximum variation sampling approach was used to capture a wide range of experiences (Coyne 1997). Twenty-eight participants lived with the person with MS.

Interviews began by inviting participants to talk about their experiences of MS from the point in time when the illness became apparent. Participants were then asked to elucidate parts of that narrative and to elaborate specific areas of interest, including the impact of MS on personal and family relationships. Interviews lasted between 20 minutes (self-recorded audio) and two hour and 15 minutes, with an average length of around 65 minutes. 


\section{Study B: Health-related internet use by people affected by MS}

Study B was a mixed-methods project on internet use and the sharing of experiences in the context of MS. Between July 2011 and August 2012, FM conducted 17 telephone interviews with people affected by MS (12 patients and five family members). Two of the family members, both spouses of the person with MS, were also interviewed in Study A. This is taken into consideration in our analysis.

The interviews explored people's experiences of using internet technologies in relation to MS. A semi-structured interview protocol was followed. The protocol had three main aims: i) to explore internet use in relation to MS and health; ii) to situate this in relation to interviewees' wider experiences of MS; iii) to develop an understanding of how the sharing and receiving of other people's experiences affected interviewees' sense of identity, wellbeing and health-related decision-making. At the end of the interview, participants were asked if any issues or topics that they thought important had not already been covered. Interviews lasted for approximately one hour.

\section{Study C: Online health experiences, the perspective of carers of people with MS}

Between October 2011 and February 2013, CH and ES carried out 20 interviews with adult family members of people with MS. The aim of the research was to examine the mechanisms that drive health-related internet searching behaviours, choice of online patient experiences, and their potential to impact the user's life.

Participants were interviewed either individually or in small group sessions. All sessions lasted two hours. During this time, participants individually viewed a number of pre-selected health-relevant websites for one hour before choosing a smaller number of sites to engage 
with further. Website selections were recorded in a log book. At the end of the session participants took part in a semi-structured interview, covering: i) overall impressions of the websites; ii) likes and dislikes; iii) the role of patient experiences; iv) affective attitude; v) selection and rejection factors; vi) congruence to existing beliefs; and vii) trust and behaviour.

\section{Combined Analysis}

As the three studies were part of a programme of work, the authors met regularly during the period of research, discussed and shared findings informally and through presentations. In 2015, we analysed all three data sets with a specific focus on how interviewees spoke of seeking and sharing information in relation to their families and wider relational networks.

For each study, the study's primary researcher extracted portions of the interviews where participants discussed their information practices in relation to family members and friends. These extracts were collated into a combined coding report. FM (primary researcher from Study B) performed a thematic analysis on the report. This resulted in seven descriptive categories: 1) managing information as part of care practices; 2) distribution of information responsibilities; 3) negotiation of needs, practices and preferences; 4) protecting each other; 5) respecting the wishes of the person with MS; 6) information and support for carers; 7) information management strategies and practices changing over time. These categories were double-checked by NH (primary researcher of Study A) and reviewed by $\mathrm{CH}$ and ES (researchers from Study C). Any discrepancies in interpretation were resolved through discussion. 
These above seven descriptive categories foreground different aspects of the inter-relational dimensions of health information management. First, we provide a high-level overview of key findings across these categories. Next, we unpack two themes that emerged out of these descriptive categories. The first explores the distributed nature of health information work within family units. The second unpacks the relationship between managing health information and care from the perspective of informal carers.

\section{Limitations}

Our analysis focuses on intra-familial information practices. Thus, it is necessarily selective, with certain practices receiving particular attention (e.g. how couples share health information with each other), while others (e.g. the role of healthcare professionals) are alluded to more briefly. Furthermore, we focus on health information work. Clearly, information that is not strictly speaking related to health or medicine play an important role in living with MS (e.g. arranging powers of attorney, benefits claims etc.). However, in order to maintain analytical focus, we will not elaborate on these other types of information work.

The majority of our interviewees were in a relationship with someone or had a close-knit support structure. We recognise that many people with MS experience a breakdown in their relationships, family or community support networks, and can become isolated. In such cases, their health information practices may well differ from those we describe. Moreover, fortynine interviewees were partners or spouses of someone with MS. As a result, the types of information work done by partner/carers receives more attention than that more typically done by patients (for example, carers were less likely to use online peer-support networks). This is particularly relevant for section 6 , where we focus on health information work as a form of care from the carers' perspective. 


\section{The inter-relational dynamics of health information work}

Our interviews regularly stated that information was critical for living well with MS. Timely access to appropriate information was understood to have real implications for patients' and their families' quality of life. It influenced, for example, collective decision-making around treatment and access to support services, as well as the family's general sense of well-being and management of everyday life (e.g. benefits, home adaptations, mobility etc.). At the same time, the sheer quantity, complexity and changeability of information that needed to be assimilated, managed and communicated (e.g. changing symptoms, biomedical innovations, technical aids, shifts in health and social care) were perceived as overwhelming, timeconsuming and, at times, emotionally distressing. Consequently, our interviewees framed information management as an important, but challenging task that required a considerable amount of practical and emotional 'work' on the part of patients and other family members.

The information work our interviewees spoke of was diverse and wide-ranging, including, but not limited to: seeking, sharing, aggregating, comparing, recording, filtering, controlling and transmitting information to the wider family and beyond, such as friends, online peersupport networks and healthcare practitioners. Forty-three interviewees were affected by MS for fifteen years or longer. They reflected on how the information and related resources (such as online peer-support) available to patients and their families had grown in terms of quantity and complexity. Digital technologies (the internet and social media platforms) were cited as enabling access to information and support from other patients as well as cutting-edge medical research. However, they were also presented as potentially harmful (e.g. propagating misinformation), time-consuming, and dependent on technical skills and competencies. 
Significantly, the increased availability of health-related information online did not automatically equate to an increased use of digital technologies, with a number of interviewees stating they actively avoided using the internet in relation to MS. For those that did use them, digital technologies were a core part of life with MS, providing access to research studies, reviews of healthcare providers, networks of support and outlets for selfexpression.

When talking about MS and health related information, our interviewees frequently mentioned how their information practices were shaped by inter-personal relationships and family dynamics. These references were underpinned by an, at times tacit, understanding of MS as a shared, rather than individual, concern. Evident in interviews with family members and friends, the framing of MS as a shared responsibility was especially pronounced in discussions with partners (for more on couples' responses to MS see Boland et al. (2012)). Thus, MS was seen as something that individuals within a relationship experienced differently, but faced 'together', and sharing a 'life with MS' often went hand-in-hand with the sharing information about it:

As soon as there's a news story on MS, which does happen quite regularly, we do find ourselves going through it with a fine-toothed comb, you know, the latest drug, the latest treatment, the latest injection. [Study A, participant 19: the husband of woman with MS, five years since diagnosis.]

Our interviewees' emphasis on sharing information (as well as on labouring through it) was balanced by an equally pronounced stress on controlling its flow into, within and beyond the family unit, with families developing their own idiosyncratic strategies for doing so. In some cases, these strategies emerged spontaneously with little overt discussion, while in others they were the result of an explicit agreement: 
And at one point we sort of made a little pact with one another that we wouldn't keep going on the internet, that we would use the MS nurse and we'd use the MS site and we would use the neurologist and the other professionals we were coming into contact with because we both felt quite strongly that that was how we were going to get our information. [Study A, participant 36: the mother of daughter awaiting definitive diagnosis.]

The above quotation describes a mother and daughter deciding together not to use the internet to search for information, preferring to trust practitioners and official websites. This is one example of how couples and families develop specific strategies for controlling the flow of information into their family. They also control its flow within the family. Our interviewees described numerous instances where they withheld, censored or otherwise mediated information relating to MS. The most common reason for withholding or filtering information within the family was to protect a loved one (especially children and older family members, but also other adults, including the person with MS) from potentially distressing information (for similar findings in relation to cancer see Thomas et al. (2002, p.541)). However, our interviewees filtered or censored information for other reasons as well (for example, when they deemed it inaccurate, irrelevant, overwhelming or sensitive in some way).

Differences in approaches to health-related information could sometimes result in tensions and even conflict. This was especially notable in situations where one or more family member (commonly the patient) resisted receiving or sharing health-related information:

My husband didn't want to know, at that point [diagnosis], what was going to happen. He was very, very much in denial for about five years before I could actually kick him up the backside and basically say, 'Sit down, read some of this information, 
it will make your life a little bit easier'. [Study A, participant 33: wife of man with MS, 25 years since diagnosis.]

In such situations, other family members, most especially spouses, felt they had a moral obligation to encourage and occasionally force the resistant party to: a) engage with information that they felt was essential for their health and well-being; b) share relevant information (for example, changes in symptoms, mental state etc.) with those close to them as well as medical practitioners and other service providers, such as social services.

\section{The intra-familial distribution of health information work}

We already know that the onset of initial symptoms and diagnosis are critical periods when some people prefer to avoid information, while others become particularly active information seekers (Wollin et al., 2000; Lode et al., 2007; Colombo et al., 2014). By looking at interrelational, rather than individual, information practices, our research shows that when one member of a couple (either the patient or their partner) avoided or ignored information, the other usually compensated by taking on the responsibility of managing it. Conversely, in cases where the patient was an avid information seeker, other family members tended to take a back seat, allowing the patient to take the lead. During periods of increased disability and as the illness progressed, family members and most especially partners, even those who had not necessarily been actively involved in managing information earlier on, tended to assume more responsibility for managing information. Thus, a key finding of our analysis was that at any given time one person, typically either the patient or their partner, but occasionally another family member, such as a parent, emerged as the main 'information worker':

My wife has done most of it. She has done a lot of the research online and has contacted various kinds for MS and support groups and she gets a regular magazine from the MS resource centre sort of she has got contact from a few people. Myself its 
largely been kind of reading the information that she's found out so I haven't

searched a great deal out of it. [Study C, participant 12: husband of woman with MS, 10 years since diagnosis.]

In some cases, the person who took on primary responsibility for managing health information became an information 'expert', pro-actively seeking, collecting and analysing a wide range of different kinds of information relating to MS and healthcare more generally. As a result, they became very knowledgeable about MS as well as proficient with different information resources and technologies, from medical databases to patient forums. Others sought and responded to information more selectively, in relation to a particular area of life, through a particular medium or support network (such as a Facebook group) they liked, or on a need-to-know basis. Changes in the progress of the disease or life more generally (e.g. wanting to start a family, moving jobs, retirement etc.), commonly precipitated a period of active information seeking, which then tapered off until the next trigger. A further category took on the work of managing information reluctantly. Here, rather than actively seeking information they relied on information passed on to them by medical professionals or other support services, responding if and when necessary. The responsibility for health information work was, therefore, not only distributed differently over time within families, the nature and extent of this work differed considerably between families.

Various reasons were given for why and how someone took on the role of managing health information. For many of our interviewees, it was a matter of personality and 'natural' abilities and inclinations, with the key information worker perceived as having better research, technical (especially internet) or communication skills. Psychological factors (e.g. 'denial') were regularly used to explain why some people avoided MS-related information. Either way, who took on the responsibility of health-related information work was not simply the outcome of personal choice, ability or inclination. It was shaped by a number of structural 
and others factors that influence who is provided with information, in what format, and when, as well as pre-existing family hierarchies and dynamics.

For example, the husband of a woman with MS had not felt comfortable requesting information in clinical contexts as he was not the patient, and it was only when a healthcare practitioner explicitly encouraged him that he felt able to do so (Study A). This highlights how unspoken assumptions on the part of patients and medical practitioners can shape the flow, or lack thereof, of information to different family members. We also found that age and gender played a role in who took on the work of managing health information. Older people and children were perceived as being less capable of dealing with information both practically and emotionally. Reflecting back on his experiences as a child of a mother with MS, one interviewee said he had not been given information about his mother's condition and had been discouraged from asking questions (Study A). A number of interviewees told us they were careful what they told elderly family members, while a few of our older participants said they relied on younger family members to make sense of technical healthrelated information.

Existing research has shown that women often take on primary responsibility for managing health information for their family (Warner and Procaccino, 2004; Koehly et al., 2009). We found a similar trend in our interviews, with women being more likely to actively seek out and share health-related information. Given that we had more female $(n=47)$ than male $(\mathrm{n}=30)$ participants and a relatively small dataset, we cannot make any general conclusions about the extent to which gender influences who manages health information in families affected by chronic illness. Nevertheless, given the highly gendered nature of informal care work more generally (Meyer 2002), it seems highly likely that gender plays a role here as well. 


\section{Health information work and the enactment of care}

Above we described, first, how health information work is shared within families, and second, how it is often unequally distributed. Although MS affects the family as a whole, it does so in different ways; the seeking, sharing or mediating of health-related information is clearly not the same for the patient, their partner or other family members. There is a fundamental asymmetry in the carer/cared-for relationship that affects the way information is managed across this dyad. This is particularly poignant in situations where one person is unable or unwilling to share the responsibility of information work. In such cases, our carer interviewees spoke not of facing MS 'together', but rather, of having to 'think for two':

I think when you're a carer you've got to be really steely. Sometimes you've got to be thinking for two people and making decisions for two people, in many instances when the person doesn't want you to be. [Study C, participant 9: husband of woman with MS, 10 years since diagnosis.]

'Thinking for two' does not mean dissolving the distinction between family member as carer and the person with MS. Rather, it implies a situation in which information work becomes a part of wider care work. There are two dimensions to this: on the one hand, information work is, inevitably, a vital element in a whole range of different caring activities (e.g. sourcing a new wheelchair, renovating the bathroom to make it more accessible); on the other, information work is a matter of managing information for another. Indeed, the informal carers that we interviewed were acutely aware of the fact that they were not the patient, but were, as carers, often needing to act on behalf of them. Many assumed this meant that they had to manage information in a manner that took into account the declared or implied preferences of the person with MS: 
I am also conscious as well that a lot of the stuff that I might be saying is breaching my wife's confidence not mine... That's something you have got to be very, very aware of, because I don't want you to disclose something that will embarrass my wife. I think you have got to be very careful of that. [Study B, participant 1: husband of woman with MS, over 20 years since diagnosis.]

Here, our interviewee explains how he tries to respect his wife's privacy when sharing health information online and in other contexts, such as clinical consultations, at times withholding or filtering information he believes she would not like shared. Conversely, instead of adhering to the patients' implicit or explicit preferences, family members spoke of disclosing or obtaining information irrespective of the patient's wishes because they, in their role of carers, felt that doing so was in the best interests of the physical or mental health of themselves, the patient or other family members. In other words, irrespective of what the carers assumed was their duty or responsibility when managing information (whether to conceal or disclose), it was done in relation to the people they cared for, making their decisions and actions an enactment of care itself.

What our data also revealed was that the information work carried out by informal carers tended to be enacted as 'care for another' even when the information that they sought was geared towards them as carers. With a few exceptions, the partners, family members and friends of people with MS that we interviewed rarely spoke of seeking information or support for themselves. When they did, their mode of 'thinking for two' prompted them to take the perspective of the person with MS:

I was actually looking day before yesterday on... now which website was it? The MS Society where they have a whole section for carers, and I did start to look through 
that, but generally I must admit I have probably looked at it from her perspective

rather than my own [..] [Study B, participant 4: mother of young woman with MS, two years since diagnosis.]

This did not mean that the families and partners of people with MS did not need information or support. Our interviewees spoke lucidly of the psychological, social and physical challenges they faced. However, many said they found information geared toward carers depressing or not particularly helpful, while others were not even aware of the existence of these services. Thus, even though patients' and their family members' can and do enact care through information practices, this is done asymmetrically, with the needs of the patients tending to take precedent over those of other family members.

\section{Conclusions}

This paper has explored the inter-relational dynamics of health information practices in couples and families affected by MS. We have suggested that managing information in the context of life-altering illness represents a form of work, and that this information should be considered a distinctive form of care in its own right. We have described different ways in which people enact care through their information practices, including how information: a) is carefully controlled and filtered to protect those deemed vulnerable, unwilling or unable to handle it (e.g. an informal carer protecting their loved one's privacy online or a patient withholding information about the severity of their symptoms); b) is actively sought and shared when deemed necessary (e.g. someone diagnosed with MS seeking out as much information as possible to understand their condition or an informal carer sharing information to encourage 'acceptance' of a diagnosis). 
The paper has further highlighted how roles and responsibilities for information work not only shift over time, but also are distributed across family units and friendship networks. These responsibilities can end up being primarily taken on by one family member, most commonly either the patient or their partner. Throughout, we have drawn attention to how being able to effectively manage health-related information is influenced by a range of factors, such as people's skills and orientations, family dynamics and preferences, nature and stage of illness, wider healthcare environment and systems for providing health information. Furthermore, while people with chronic illness, their partners, family members and close friends all respond to and, in many cases, actively manage health information, information work and the responsibilities that accrue from it take on a particular character when done by someone other than the patient.

Thus, while our analytical emphasis on information work as care work blurs the distinction between 'carer' and 'cared for', foregrounding the reciprocal nature of caring relations, it also brings asymmetries in intra-familial health information practices to light. Even though information work cannot be simplistically classified as a 'burden', informal carers often do find it time-consuming and challenging, especially when they take on responsibility for it reluctantly. Moreover, despite the fact that both patients and informal carers can take on the role of key information worker, the information around which this work centres typically remains focused on the illness and the person with the illness, while the issues that carers may have are usually placed, almost by default, as secondary.

With a few exceptions (Hogan and Palmer, 2005; Souden, 2008), little attention has been paid to the information work that patients and their families perform as part of living with chronic illness. Today, patients and their families are required to deal with complex, often 
highly technical, information, and are increasingly expected to make critical health decisions based on this. Given the emphasis placed on informed choice in contemporary healthcare, coupled with a tendency to delegate responsibility for managing information to patients, we argue that the invisible and unacknowledged work of managing ever-growing quantities of health and medical information needs to be studied in more depth across different conditions and contexts. In this paper, we have contributed to this broader project by moving beyond the tendency within research on health information practices to focus on patients and have instead emphasised the inter-relational dynamics of information practices within (broadly defined) family units, with particular focus on the role of informal carers.

\section{Implications for Practice}

Research on how people cope with MS suggests that the 'coping style' of the couple, rather than the individual, is key, and recommends that psychological interventions target both patient and carer (Pakenham, 1998, p.276). Similarly, when developing information services for people affected by MS (both patients and carers) - something that extant research constantly reiterates needs improvement (Hepworth and Harrison 2004; Bogosian et al. 2009; Corry and While 2009) - it is important that partners and other family members are taken into consideration. This is especially important given that carers are unlikely to foreground their own needs or concerns. Our research suggests that it is hard to generalise about people's information practices and preferences, so practitioners need to give them various options and services that they can access in their own time. It may be helpful for healthcare practitioners to ascertain who the key 'information worker' is within a family, so that they can ensure they as well as the patient receive the necessary information. Lastly, it is important to recognise that the management of information constitutes part of the work of living with chronic illness (for both patients and informal carers). This work is time-consuming, emotionally fraught and 
complex, and needs to be recognised as such to avoid overly simplistic equations of more information with increased patient power and control. 


\section{References}

Ayers, S.L. and Kronenfeld, J.J. (2007) Chronic illness and health seeking information on the Internet. Health: An Interdisciplinary Journal for the Social Study of Health, Illness and Medicine, 11, 3, 327-47.

Boeije, H.R., Duijnstee, M.S.H. and Grypdonck, M.H.F. (2003) Continuation of caregiving among partners who give total care to spouses with Multiple Sclerosis. Health and Social Care in the Community, 11, 3, 242-52.

Boeije, H.R., Duijnstee, M.S.H., Grypdonck, M.H.F. and Pool, A. (2002) Encountering the downward phase: Biographical work in people with Multiple Sclerosis living at home. Social Science and Medicine, 55, 6, 881-93.

Bogosian, A., Moss-Morris, R., Yardley, L. and Dennison, L. (2009) Experiences of partners of people in the early stages of Multiple Sclerosis. Multiple Sclerosis, 15, 7, 876-84.

Boland, P., Levack, W.M.M., Hudson, S. and Bell, E.M. (2012) Coping with Multiple Sclerosis as a couple: 'Peaks and troughs' - an interpretative phenomenological exploration. Disability and Rehabilitation, 34, 16, 1367-75.

Cheung, J. and Hocking, P. (2004) Caring as worrying: The experience of spousal carers. Journal of Advanced Nursing, 47, 5, 475-82.

Colombo, C., Mosconi, P., Confalonieri, P., Baroni, I., Traversa, S., Hill, S.J., Synnot, A.J., Oprandi, N. and Filippini, G. (2014) Web search behavior and information needs of people with Multiple Sclerosis: Focus group study and analysis of online postings. Interactive Journal of Medical Research, 3(3): e12.

Compston, A. and Coles, A. (2008) Multiple Sclerosis. The Lancet 372 (9648): 1502-17.

Corbin, J. M., and Strauss, A.L. (1988) Unending work and care: Managing chronic illness at home. San Francisco: Jossey-Bass Publishers.

Corbin, J.M. and Strauss, A.L. (1984) Collaboration: Couples working together to manage chronic illness. Image: The Journal of Nursing Scholarship, 16, 4, 109-15.

Corry, M. and While, A. (2009) The needs of carers of people with Multiple Sclerosis: A literature review. Scandinavian Journal of Caring Sciences, 23, 3, 569-88.

Coulter, A. (2010) Do patients want a choice and does it work? British Medical Journal 341 (October): c4989.

Coulter, A., Entwistle, V. and Gilbert, D. (1999) Sharing decisions with patients: Is the information good enough? British Medical Journal, 318 (7179): 318-22.

Coyne, I. (1997) Sampling in qualitative research: Purposeful and theoretical sampling: merging or clear boundaries? Journal of Advanced Nursing, 26, 623-30.

Dyck, I. (1995) Hidden geographies: The changing lifeworlds of women with Multiple Sclerosis. Social Science and Medicine, 40, 3, 307-20. 
England, K. and Dyck, I. (2011) Managing the body work of home care. Sociology of Health and Illness, 33, 2, 206-19.

Green, G., Todd, J. and Pevalin, D. (2007) Biographical disruption associated with Multiple Sclerosis: Using propensity scoring to assess the impact. Social Science and Medicine, 65, 3, 524-35.

Henwood, F., Wyatt, S., Hart, A. and Smith, J. (2003) 'Ignorance is bliss sometimes': Constraints on the emergence of the 'informed patient' in the changing landscape of health information. Sociology of Health and Illness, 25, 6, 589-607.

Hepworth, M. and Harrison, J. (2004) A Survey of the information needs of people with Multiple Sclerosis. Health Informatics Journal,10, 1, 49-69.

Hinton, L., Kurinczuk, J.J. and Ziebland, S. (2010) Infertility, isolation and the Internet: A qualitative interview study. Patient Education and Counseling, 81, 3, 436-41.

Hogan, T.P. and Palmer, C.L. (2005) 'Information work' and chronic illness: Interpreting results from a nationwide survey of people living with HIV/AIDS., In 68th Annual Meeting of the American Society for Information Science and Technology (ASIST), Charlotte (US), 28 October-2 November 2005.

Hughes, N., Locock, L. and Ziebland, S. (2013) Personal identity and the role of 'carer' among relatives and friends of people with Multiple Sclerosis. Social Science and Medicine, $96,78-85$.

James, N. (1992) Care = Organisation + Physical Labour + Emotional Labour. Sociology of Health and Illness, 14, 4, 488-509.

Johnson, J. (2003) On receiving the diagnosis of Multiple Sclerosis: Managing the transition. Multiple Sclerosis, 9, 1, 82-88.

Kinnane, N.A. and Milne, D.J. (2010) The role of the Internet in supporting and informing carers of people with cancer: A literature review. Supportive Care in Cancer, 18, 9, 1123-36.

Kivits, J. (2004) Researching the 'informed patient': The case of online health information seekers. Information, Communication and Society, 7, 4, 510-30.

Koehly, L.M., Peters, J.A., Kenen, R., Hoskins, L.M., Ersig, A.L., Kuhn, N.R., Loud, J.T. and Greene, M.H. (2009) Characteristics of health information gatherers, disseminators, and blockers within families at risk of hereditary cancer: Implications for family health communication interventions. American Journal of Public Health, 99, 12, 2203-9.

Ley, P. (1982) Satisfaction, compliance, and communication. British Journal of Clinical Psychology, 21, 241-54.

Lode, K., Larsen, J.P., Bru, E., Klevan, G., Myhr, K.M. and Nyland, H. (2007) Patient information and coping styles in Multiple Sclerosis. Multiple Sclerosis, 13, 6, 792-99.

Marrie, R.A., Salter, A.R., Tyry, T., Fox, R.J. and Cutter, G.R. (2013) Preferred sources of health information in persons with Multiple Sclerosis: Degree of trust and information sought. Journal of Medical Internet Research 15 (4): e67. 
Mazanderani, F., Locock, L. and Powell, J. (2012) Being differently the same: The mediation of identity tensions in the sharing of illness experiences. Social Science and Medicine, 74, 4, 546-53.

McAlpine, D. and Alastair C. (2005) McAlpine's Multiple Sclerosis. Elsevier Health Sciences.

McIntosh, J. (1974) Processes of communication, information seeking and control associated with cancer: A selective review of the literature." Social Science and Medicine, 8, 167-87.

McKinlay, J.B. (1972) Social networks, lay consultation and help-seeking behavior. Social Forces, 51, 3, 275-92.

Meyer, M.H. (2002) Care Work: Gender, Labor, and the Welfare State. London: Routledge.

Murray, T. J. (2006) Diagnosis and treatment of Multiple Sclerosis. British Medical Journal, 332 (7540): 525-27.

Mutch, K. (2010) In sickness and in health: Experience of caring for a spouse with MS. British Journal of Nursing, 19, 4, 214-219.

Nettleton, S., Burrows, R., O’Malley, L. and Watt, I. (2004) Health e-types? An analysis of the everyday use of the Internet for health. Information, Communication and Society, 7, 4, 531-553.

Orgad, S. (2006) The cultural dimensions of online communication: A study of breast cancer patients' Internet spaces. New Media and Society, 8, 6, 877-99.

Pakenham, K. I. (1998). Couple Coping and Adjustment to Multiple Sclerosis in Care Receiver-Carer Dyads. Family Relations 47, 3, 269-77.

Powell J. and Boden S. (2012) Greater choice and control? Health policy and the online health consumer. Policy and Internet, 4, 2, 1-23.

Powell, J., Gunn, L., Lowe, P., Sheehan, B., Griffiths, F. and Clarke, A. (2010) New networked technologies and carers of people with dementia: An interview study. Ageing and Society, 30 (06): 1073-88.

Reynolds, M. (1978) No news is bad news: Patients' views about communication in hospital. British Medical Journal, 1 (6128): 1673-76.

Richardson, J.C., Ong, B.N. and Sim, J. (2007) Experiencing chronic widespread pain in a family context: Giving and receiving practical and emotional support. Sociology of Health and Illness, 29, 3, 347-65.

Riley, R. and Weiss, M.C. (2016) A qualitative thematic review: Emotional labour in healthcare settings. Journal of Advanced Nursing, 72, 1, 6-17.

Robinson, I. (1990) Personal narratives, social careers and medical courses: Analysing life trajectories in autobiographies of people with Multiple Sclerosis. Social Science and Medicine, 30, 11, 1173-86. 
Scambler, A., Scambler, B. and Craig, D. (1981) Kinship and friendship networks and women's demands for primary care. Journal of the Royal College of General Practitioners, $26,746-50$.

Sillence, E., Hardy, C., Briggs, P. and Harris, P.R. (2015) How do carers of people with Multiple Sclerosis engage with websites containing the personal experiences of other carers and patients? Health Informatics Journal, 22, 4, 1045-1054.

Souden, M. (2008) Information work in the chronic illness experience. Proceedings of the Society for Information Science and Technology, 45(1): 1-6.

Strauss, A.L. and Corbin, J. (1985) Managing chronic illness at home: Three lines of work. Qualitative Sociology, 8, 3, 224-247.

Synnot, A.J., Hill, S.J., Garner, K.A., Summers, M.P., Filippini, G., Osborne, R.H., Shapland, S.D.P., Colombo, C. and Mosconi, P. (2014) Online health information seeking: How people with Multiple Sclerosis find, assess and integrate treatment information to manage their health. Health Expectations, 19, 3, 727-737.

Talley, C. (2008) A history of Multiple Sclerosis. $1^{\text {st }}$ Edition. Westport: Praeger Publishers Inc.

Thomas, C., Morris, S.M. and Harman, J.C. (2002) Companions through cancer: The care given by informal carers in cancer contexts. Social Science and Medicine, 54, 4, 529-44.

Tremlett, H., Paty, D. and Devonshire, V. (2006) Disability progression in Multiple Sclerosis is slower than previously reported. Neurology, 66, 2, 172-77.

Tuffrey, C. and Finlay, F. (2002) Use of the Internet by parents of paediatric outpatients. Archives of Disease in Childhood, 87, 6, 534-36.

Warner, D. and Procaccino, J.D. (2004) Toward wellness: Women seeking health information. Journal of the American Society for Information Science and Technology, 55, 8, 709-30.

Washington, K.T., Meadows, S.E., Elliott, S.G. and Koopman, R.J. (2011) Information needs of informal caregivers of older adults with chronic health conditions. Patient Education and Counseling, 83, 1, 37-44.

Williamson, C., Simpson, J. and Murray, C.D. (2008) Caregivers' experiences of caring for a husband with Parkinson's Disease and Psychotic Symptoms. Social Science and Medicine, $67,4,583-89$.

Wollin, J.A., Yates, P.M. and Kristjanson. L.J. (2006) Supportive and palliative care needs identified by Multiple Sclerosis patients and their families. International Journal of Palliative Nursing, 12, 1, 20-26.

Wollin, J.A., Dale, H., Spencer, N.M. and Walsh, A. (2000) What people with newly Diagnosed Multiple Sclerosis (and their families and friends) need to know. International Journal of MS Care, 2, 3, 29-39. 
Ziebland, S. (2004) The importance of being expert: The quest for cancer information on the Internet. Social Science and Medicine, 59, 1783-93.

Ziebland, S. and Wyke, S. (2012) Health and illness in a connected world: How might sharing experiences on the Internet affect people's health? Milbank Quarterly, 90, 2, 219249. 